[Davies, J. (1999). Constructing Technology Education: Questions of Purpose and Fit. New Zealand Annual Review of Education, 8, 119-146]

\section{Constructing Technology Education: Questions of Purpose and Fit}

\author{
JANET DAVIES
}

\section{Abstract:}

The technology curriculum comes into effect this year, designed to make school leavers innovators for the future. Teaching and learning is to be built around technological problem-solving as a "purposeful activity" where "fitness for purpose" is the criterion of success. This paper questions the goal of preparing students to become innovators for a future conceptualised in terms of current ideology, namely, national competition in a global market, and asks whether classroom activities that reflect current technological practice fit even this purpose. It suggests that in a late industrial society, fast becoming a "risk" society, understanding of the role of social organisation and cultural values in technological change is the primary goal, and critical technological literacy the means of its realisation. The paper examines the origins of the technology curriculum, both educational and political, the development and nature of the curriculum statement, and the progress to date of curriculum implementation in schools.

$\mathrm{T}$

he introduction of technology education to compulsory schooling comes at a time of scholarly reconceptualisation of the nature of technology. The work of historians, especially, has shown that it is no longer possible to understand technology as the application of science (Staudenmaier, 1985). Most often technology derives from existing technology, and where technology receives contributions from science, the scientific knowledge has first to be reconstructed (Kline, 1987). The politics inherent in existing technologies (Winner, 1980) and the values of the social groups which are positioned, and choose, to develop them combine in shaping new technologies (Bijker, 1995). "Technology" comprises the cultural values, social organisation and technique, inclusive of resources and products, of technology practice

\section{Janet Davies}

(Pacey, 1983). Products range from physical artefacts through less tangible social systems to knowledge, and in an emerging "risk" society, the consequences of recent technologies have implications for society and the natural environment reaching far beyond the time and place of their development (Beck, 1992; Giddens, 1994).

Understanding of discipline-based education, too, is being revised to include, not only learningin constructed disciplinary knowledge, but learning about its construction (Pitt, 1990). Curriculum developers in the new school subject technology have the opportunity to learn from this, and incorporate both technological knowledge and intellectual and practical components of technique and the history and sociology of technological change. These dimensions together contribute to critical technological literacy, and so support liberal education. Attention to contemporary technological knowled ge and methods alone will provide only functional literacy, limited to operation within its supporting belief systems (Layton, 1992).

\section{Origins of Compulsory School Technology}

Technology education as a component of compulsory schooling has been constructed in New Zealand and elsewhere over the last 20 years to support an "enterprise culture" and national competitiveness in an international marketplace. In New Zealand, political and economic origins can be identified in the reorganisation of science, technology and education from the mid-1980s, and educational origins seen in the reconceptualisation of learning in science and technical subjects that began somewhat earlier.

\section{Educational origins}

From the late 1970s, interest among technical teachers in the expansion of their subjects led to the more technologically oriented workshop technology at secondary level (Department of Education, 1984), and workshop craft at intermediate level (Department of Education, 1986). These subjects introduced a common design brief to class workshop activities, and thus an element of design to the preliminary stages of making an artefact, and expanded the materials used beyond wood and metal to include, typically, ceramics and plastics. Some consideration of environmental impact was also introduced. Home economics teachers promoted development beyond the technical in subjects such as "design for living". These technology-related subjects, however, drew minimal and still stereotypically gendered increases in student uptake 
(Burns, 1992), although interest among all students in the new computer studies subjects developed rapidly.

Developments in science teaching in the early 1980s saw limited introduction of the international Science, Technology and Society movement (Burns \& Knedler, 1984; Green, 1984). From this perspective, meaningful study in science occurs when the relationship between science, technology and society is taken into account. For example, examination of the health risks of lead in the environment and the use of tetra-ethyl lead in boosting car performance, renders significant the development of understanding of the reactions of lead. In another approach promoted at that time, technological applications were seen as a valuable context from which to develop learning in science (Cosgrove \& Mueggenberg, 1986; Jones, 1990). Thus investigation of the workings of a refrigerator or a camera flash unit could lead to knowledge of latent heat or electrical capacitance. In this approach, the technological application is a vehicle for the development of understanding of science concepts and a familiar starting point for student learning.

The 1980s also saw increasing concern for the development of appropriate science programmes for girls and for Maori, with new approaches to learning and an understanding of science that went beyond the bounds of the certainty and exclusiveness of western science. These concerns were evident in the recommendations of the community-based Curriculum Review (Department of Education, 1987). A broader conception of school science as an integrated study of "Science, Technology and the Environment" was proposed in the National Curriculum Statement (Department of Education, 1988a), where the traditional focus on understanding the natural world was extended to include "the technological world" (p. 12), and responsibility "in using and controlling" science and technology, and appreciation of how "cultures relate to, use, and conserve the environment" were added (p. 13). In this curriculum the focus was on the learners, their success and enjoyment, a balanced education and the development of a sense of cultural identity and equity for all students.

\section{Political and economic origins}

While the quality of school science education was of concern to science educators, the declining proportions of students taking science at senior school and tertiary levels drew calls from professional scientists and technologists and fromindustry (Clark \& Vere-Jones, 1986; Walsh, 1987) for more rather than different school science education, through longer compulsory science education and raising of the school leaving age. The calls supported a closer link between education, industry and business (Blakeley, 1991; Monteith, 1987).

The report of the Ministerial Working Party on Science and Technology (New Zealand Government, 1986) laid the ground for the commercialisation of science and the promotion of its links with technology in the belief "that harnessing science and technology into the wider economic and social development process should be a major national objective" (p. vi). Recommendations for education highlighted the preparation of technologists. While the report also recognised New Zealanders' concern with "quality of living" (p. vi), economic goals were primary and social development was expected to follow. The establishment of the Science and Technology Advisory Committee, and ultimately the Ministry of Research, Science and Technology, raised the profile of technology, although it remained subservient to science in the widely held view of technology as applied science (Ministry of Research, Science and Technology, 1991). With the election of the National Government in late 1990, the economic argument for the expansion of science and technology became apparent in the priorities set for funding through the Public Good Science Fund, administered by the Foundation for Research, Science and Technology (Doig, 1991) and more recently extended to include university research funding. The new government's Achievement Initiative (Ministry of Education, 1991a), in a programme of performance assessment and efficiency, introduced technology to compulsory schooling, despite its previous absence from the curriculum in New Zealand, and little reported experience elsewhere. Technology was subsequently identified as one of the seven essential learning areas in The National Curriculum of New Zealand: A Discussion Document (Ministry of Education, 1991b), which aimed to support success in "the modern, competitive economy" (p. 1).

\section{Articulation of a School Technology Curriculum}

The introduction of technology education in support of increased research and development for business enterprise and economic growth determined the shape of policy in this new area of learning. It was effected through the separation of policy advice from policy implementation (Boston, 1991) in the managerialism that was set up by the previous Labour government to prevent "provider capture". Premised on an unsupported view of individuals as primarily 
self-interested, it fails to avoid other forms of capture, such as "ideological capture". Contractual arrangements with outside bodies for the writing of curriculum statements, and in the case of technology a policy framework as well, ensured that policy directives were met.

\section{Policy development}

The decision to introduce technology education generated considerable interest among educators in technology-related areas, especially those who had been involved in moves by the Department of Education's Curriculum Development Unit in the late 1980s to investigate possibilities for technology education (Fergusson, 1997). While a proposal for its introduction (Department of Education, 1988b), generated at a national teachers' course was not then pursued, research (Burns, 1990) and development activities in schools (see, for example, Kerse, 1989) were initiated. Interest was, however, tempered with caution. Following the release of the Discussion Document, Farmer and Hodson (1991) asked whether, in view of the link with economic development, the new subject would focus, as in England and Wales, on technological problem-solving or be about technology, in the tradition of the Science, Technology and Society movement. Jesson (1991) questioned the point of technology education, suggesting an examination of the interests of the companies promoting the subject. There was thus early recognition of the divergent paths that technology education could take.

In 1991 the Ministries of Research, Science and Technology and Education established a task group representing industry, tertiary science, science teachers and teacher trainers to review science and technology education. The group reported the following year (1992), making recommendations for the introduction of compulsory technology education and the urgent development of a curriculum statement. A government-appointed working party early in 1992, again with industry and education representation, but with a focus on engineering, technology and technical subjects, explored the development of technology education, exhibiting among its own members the widely differing perspectives that have been identified (Layton, 1993) as those of stakeholders elsewhere, from economic instrumentalism to liberal democracy (Burns, 1992; Monteith, 1992).

In the absence of an established culture of technology education, a contract for the preparation of papers for the development of a policy framework was let to the University of Waikato Science and
Mathematics Education Research Centre (now the Centre for Science, Mathematics and Technology Education Research), in particular to Dr Alister Jones, a member of the technology education working party, and Dr Malcolm Carr who had been a member of the Ministerial task group reviewing science and technology education. Dr Jones had recently returned from research in the United Kingdom with Professor Paul Black, whose work (Black \& Harrison, 1985) had contributed to the development of the curriculum in technology for England and Wales. Black and Harrison outlined a tripartite structure for technology education, namely, technological awareness, technological capability and technological literacy (understood as knowledge), already identified for curriculum technology here (Ministry of Education, 1992). Six papers addressing various aspects of policy were published the following year (Jones \& Carr, 1993a), and their influence in the development of a framework for technology education is acknowledged by the Minister of Education in the foreword to Technology in Schools (Ministry of Education, 1993a).

Other researchers writing at that time foreshadowed much of what appeared in the framework, including a conceptualisation of technology as separate from science, the tripartite structure for technology education, and open-ended technological problem-solving set in "real world" contexts. Hodson and Farmer (1992) also supported the notion of critical technological awareness, and Verbowski (1992a, 1992b) took this further, drawing attention to the negative face of technology and the need to educate for wise decision-making. Technology education he said should not be given over entirely to technological capability, questioning how students would "gain the understanding for value judgements about technology" (1992b, p. 12).

In the foreword to the policy framework, the Minister of Education presents an economic rationale for the introduction of technology education, a rationale which had narrowed considerably from that put forward the previous year in So This Is Technology! (Ministry of Education, 1992), which had placed "students' needs" and "the environment (human and ecological)" alongside "the economic growth of New Zealand" (p. 4). The economic rationale mirrors that for introducing the technology curriculum in England and Wales (Department of Education and Science, 1990), as does the requirement that an holistic approach to student learning will be undertaken through technological problem-solving activities. These activities contribute to the general aim of technological capability, as in England 
and Wales, but also to two further general aims, technological knowledge - typical of revisions of the first curriculum in England and Wales and of other later curricula such as that in Australia (Curriculum Corporation, 1994) - and, in a departure from these curricula, understanding of the relationship between technology and society. In the development of achievement aims, however, ca pability is expanded, as in the curriculum of England and Wales, to provide four such aims and thus the significance of technology and society is substantially reduced. Burns has argued (1993), that this step, together with the determinist understanding of technology (whereby people must learn to adapt to inevitable technological change), and the dependence on "skills", made it unlikely that students would develop a critical technological literacy that would allow them to make significant life choices.

\section{Development of a national curriculum statement}

The Ministry returned to the writers of the policy papers, in 1993, for the drafting of a curriculum. Jones (1998) reports involving over 300 people, mainly school teachers, in the writing and development process. Teachers, however, according to concurrent research of the contractors (Jones \& Carr, 1992), were poorly informed about the nature of "technology" and of what technology education might involve. Here as elsewhere (Paechter, 1991), teachers interpreted technology education in terms of their disciplinary background. Their time working on the draft curriculum thus served as an apprenticeship in the developing technology education culture of the Centre. An Advisory Committee to the Minister of Education, mainly male and comprising representatives of ind ustry, school teaching and university engineering and technology (Ministry of Education, 1993b, p. 127), met to advise on each of the three milestone reports of the contract. A Review Committee of the Ministry of Education, mainly female and representative of school teaching and university technology and education, met to discuss adherence to the contract of the first two reports only. It could be suggested that the construction of the committees strongly favoured approval of a curriculum supporting an economic instrumentalist philosophy designed to achieve government goals of entrepreneurship and national economic growth.

The development of the curriculum statement was informed by the contractors' Learning in Technology Education (LITE) research project, funded by the Ministry of Education, which investigated the development of technological capability among primary and secondary students in three schools. While this research is described as exploring "current practice" in technology education, in the absence of any experience of technology education, practice had first to be taught. "The notion of technological capability, as defined by the project team, was introduced to the group of teachers..." (Jones, Verbowski \& Carr, n.d., p. 5) and, through subsequent discussion with teachers, classroom tasks and guidance booklets for students were developed. Analysis of student technological capability when engaging with these tasks was reported (Jones \& Carr, 1993b) to show primarily "design and make" activity with, in some cases, inclusion of "research" which explored the "needs" of the consumers and knowledge of the materials that would be used.

The tasks - for example, "to design a pencil container so that we can keep our pencils safe" (p. 10) - were continuous with those of the "design and make" activities of workshop technology. While the tasks no longer employed close specifications in a design brief, encouraging individuality in the student's or preferably student group's design, student activities generally followed a linear process. Where information was gathered in any "research", its use for reflection regarding the overall task was reported as rare. The tasks, however, left room only for technical decision-making with regard to "fitness for purpose"; neither critical examination of the purpose, nor of values inherent in decision-making with regard to fitness, was required. In whose view, for example, is a container the most appropriate response to the issue of safety, and whose interests are served in its construction of particular materials? In the development of strategies to enhance student capability in the final phase of the LITE research (Jones, Mather \& Carr, n.d.), the major recommendation was for teachers to develop links with technological communities and "experience a level of technological enculturation" (p. 46). Promisingly, Jones et al. propose teachers' subsequent "critical analysis of ... this enculturation", but the means to challenge the adopted values and beliefs are not developed.

The draft curriculum statement (Ministry of Education, 1993b) confirmed the direction of the policy framework in six curriculum strands, of which five were concerned with the technical aspect of technology (Pacey, 1983). The notion of student empowerment was in troduced, but students were to be empowered only to make informed choices in the use of technology and in response to change. The draft was distributed widely, inviting comment from schools and the community at large, and the deadline for comment was extended to the 
end of 1994. Generally favourable responses were received from an identified sample of schools (Visser \& Bennie, 1995), and responses from primary schools were more favourable than those from secondary schools; but the overall response rate was only just over 50 percent.

The two responses sought by the business- and school-based Education Forum offer comment in rather different directions. That by Andrew Breckon, an education inspector from the United Kingdom with a background in school design and technology, contributed to the Education Forum's submission on the draft (Education Forum, 1994). It proposed a sharper focus on designing and making, and the removal of the technology and society strand. The other, by the Professor of Science Education at the University of Leeds, Edgar Jenkins (1994), endorsed recognition of the interdependence of technology and science and their relationship with society, and drew attention to the difference between this view of technology and the applied science view evident in the science curriculum statement (Ministry of Education, 1993c). For this latter response the Education Forum provided a disclaimer.

\section{Nature of the Curriculum Statement}

In the final curriculum statement (Ministry of Education, 1995) the tripartite structure of the curriculum is restored in three curriculum strands, but though elaboration of these strands into achievement objectives retains a pparent equivalence of emphasis, their expression in terms of progressive levels soon dispels such myth. The capability strand characterises the structure of technological problem-solving and activities, that "usually lead to a tangible outcome" (p. 16), through which learning and teaching technology is to be undertaken. It is thus clearly the key strand. The technological knowledge and understanding strand is identified as intimately involved in technological problemsolving, yet includes only technical knowledge, while the technology and society strand encourages a broad awareness and understanding of the positioning of technological developments in society yet is unclear how this can be incorporated into temporal technological problem-solving. The term "technological", as used in the curriculum document, refers to new inventions, the term "technical", by implication, to choice between known methods and, according to Pacey (1983), these definitions reflect the approach of economists. This approach militates against technological problem-solving that considers social organisation and values as well as technical aspects. It promotes what Pacey describes as "tunnel vision" and "the technical fix", for example, the development of "green" products rather than change in underlying consumerism (Shannon, 1994). The curriculum strands are identified as contributing to the overarching aim of "technological literacy", for which there is no clarification of meaning beyond the allied statement that technology education "seeks to empower students to make informed choices in the use of technology and in their responses to technological change" (p. 8). Without a background in technology studies, student "empowerment" is limited and adaptive.

It has been argued (Burns, 1997) that, while articulation of the technology in society strand has been extended to include the influences of society on technological development as well as the impacts of technological developments on society, the achievement objectives shy away from explicit identification of social and environmental problems associated with technological change at either local or global levels, preferring to bury such issues in general statements about complexity in societal relationships, priorities in decision-making and attitudinal differences. There are few learning examples of this strand and they fail to enable examination of values issues arising in the required problem-solving tasks. Critical examination of technological practice, as an area of social practice (Gee, 1996), occurs when conflicting Discourses (with a capital " $\mathrm{D}$ ") - the practices, values and beliefs or "ways of being in the world" of different social groups - are brought together, so that the values and beliefs of one may be examined in the light of the other. Thus while fluency in a technology Discourse, and correspondingly literacy in the technology practice, is acquired by adoption of the practices, values and beliefs of the relevant community, "liberating" technological literacy is likely to be developed when apprenticeship to the technology Discourse parallels apprenticeship to another Discourse with conflicting values, such as may be found in feminism, indigenous philosophies or in technology studies more generally (Davies Burns, in press).

Although teachers can use the curriculum statement to develop classroom programmes which pursue liberating technological literacy, this is reliant on their bringing to the document knowledge that lies outside it. The curriculum statement in English (Ministry of Education, 1994a), on the other hand makes critical thinking a primary process in each of its oral, written and visual language strands. Language and the texts by which it is conveyed are thus implicitly recognised as technologies, but technologies that may be critically examined, while those identified in the technology curriculum, such as cars and 
computers, may not. Similarly, while values issues are introduced in other curriculum statements, including sustainability in social studies (Ministry of Education, 1997a) and sensitivity to the fragility of the natural environment in science (Ministry of Education, 1993c), they are not examined explicitly in technology. Motivation for the absence of these dimensions from the technology curriculum is consistent with the priority of government aims for this subject, namely, to increase economic productivity.

Many New Zealanders, however, are worried about the directions of technological change. In the latest survey of attitudes towards technology (Ministry of Research, Science and Technology, 1998), only 11 percent of people believed the benefits of nuclear power outweighed the costs, and in gene technology, where far less is known (although much is promised), the proportion is still small, at 23 percent. In a study nearly a decade old, Burns (1990) found significant numbers of thirteen year-old school students were concerned about the detrimental effects of technological change. If these concerns are not addressed in school technology, the subject will become just another where school learning is seen as irrelevant to "real life".

The technology document pursues collaboration with business, extending the promotion of links with "community" in the draft document to "community and enterprise" (Ministry of Education, 1995, p. 17) and directing schools to work together with organisations outside the school (Ministry of Education, 1993d), most of which originate in business and industry. O'Neill and Jolley (1996/97) identify "marketisation" in their consideration of food technology in the curriculum where commercial food production is promoted over food production in the home, and supports remodelling of the individual as "rational-market-man", where woman is by implication "irrational". Snook (1997) argues that the technology curriculum is ideological in setting out "to create a new kind of person for a society engineered towards certain interests which are presented as neutral and inevitable" (p. 6).

The focus on market competition reinforces understanding of technology as western patented products, neglecting technologies that are "not for profit" or are in the service sector, such as health and tourism, respectively, that would otherwise provide opportunities for the development of less tangible products. In so doing the curriculum perpetuates western failure to recognise as technology nonwestern and traditional women's technologies and thus reinforces the differential involvement of social groups, despite exhorting teachers to develop programmes appropriate for all students. Further, constrained choice within the "technological areas" available for the development of technological problem-solving is particularly significant for young men, who may leave school without education in food technology or in textile technology (which is an avoidable aspect within materials technology). Only one of the learning examples, a hangi, addresses Maori technology and none addresses technologies of other ethnic groups.

A draft technology curriculum statement in Maori, Te Tauaki Hangarau i roto i Marautanga o Aotearoa (Ministry of Education, 1998a), has been developed under contract and distributed for comment to schools and the community at large. Reconceptualisation of the learning area from a Maori cultural perspective is evident in the two-part structure for technological literacy, namely, matauranga hangarau (technological knowledge and understanding) and hangarau a-iwi (technology in society), as both these strands are seen to contribute to nga pumanawa hangarau (technological capability). However, development of this curriculum statement in the context of a published technology curriculum statement in English raises a tension between possibilities for a culturally appropriate curriculum and translation of the English version. McKinley (1996) has observed that, because of time constraints, the science curriculum in Maori (Ministry of Education, 1994b) became largely a translation of the English language version. How far expression of an appropriate conceptualisation of the technology curriculum in Maori is possible is at issue when Durie (1997), for example, identifies fundamental differences in philosophies underlying technological development.

While the English version of the technology curriculum is to be implemented through the expression of capability in classroom technological problem-solving activities, there is little empirical research into the nature of such activities (Murphy \& McCormick, 1997) and none to support technological problem-solving as the best or even as a successful way to teach technology. The most extensively researched understanding of the way in which student capability in technological problem-solving develops is found in Kimbell's (1994) model of increasing depth of performance as students uncover layers of meaning in the task, though the model is debated (see Solomon \& Hall, 1996). In Kimbell's model, which has underpinned thinking in the development of the curriculum here, performance is judged holistically. However, 
while it is possible to conceptualise progression in holistic performance, the model does not validate particular levels in this progression, since the research evidence is lacking, and does not justify the separation of such holistic performance into component parts (achievement objectives) and progressive levels in each of these. Progressive levels per se have been critically examined elsewhere (Elley, 1996) and the problems identified in sequencing learning and standardising progression across all subjects are especially acute in technology, where understanding of student learning is so limited. The identified levels simply form an ordered semantic sequence.

\section{Implementation of the Curriculum}

Implementation of the technology curriculum statement has been deferred several times and reasons given include the strains experienced by teachers, especially primary teachers, who are implementing a number of new curriculum statements, and industrial action by secondary teachers. The result has, nevertheless, ensured a carefully managed national programme of teacher development and integrated resource preparation, and more time for the development of school programmes.

An early attempt to accelerate this process served only to demonstrate the powerful influence of both prevailing assumptions about the significance of information technology and the influence of teachers' disciplinary backgrounds. In 1993, at the time of the release of the policy framework (Ministry of Education, 1993a) a government initiative offered the provision of up to $\$ 400,000$ to each of four secondary schools to develop technology education over a three year period (1994-1996). These schools were to act as community centres for technology education and as "lighthouse schools" in the national implementation of technology education. The evaluation (Hawk, 1997), however, reported investment of large sums of money in information technology and electronically controlled technical equipment, and the development of programmes for learning with computers. While some progression from this view is apparent as the projects developed and staff undertook professional development, the enormity of the task was at times found very stressful.

\section{Professional development}

Since 1994, government has contributed \$22 million to professional development activities in technology education. These monies have supported the work of newly appointed technology advisors to schools, based in the colleges of education, and teacher development contracts in technology, let mainly to the colleges of education, but also to universities and private providers. Contract specifications have supported school-based teacher development and the use of resources prepared by the Ministry (Ministry of Education, 1997b-d). While colleges of education have a legislated responsibility to government, the uncertainty of continued funding has encouraged a culture of compliance among all providers. The contracts were extended in 1995 and 1996 to include the training of technology education "facilitators" by the University of Waikato Centre for Science, Mathematics and Technology Education Research. In each year, fifteen teachers in nationally representative samples undertook a Masterate technology education paper, beginning studies in the summer and augmenting these with collaborative work with teachers in schools in their own communities (Compton \& Jones, 1998). Advisors, professional development contractors and graduates of the facilitator programmes, most of whom have been employed subsequently in facilitation work, have been invited to participate in regular conferences provided by the Ministry of Education.

In a contemporaneous programme for selected science and technology teachers, the Ministry of Research, Science and Technology has funded, and the Royal Society of New Zealand administered, between 15 and 20 New Zealand Science and Technology Teacher Fellowships annually since 1994 (Royal Society of New Zealand, n.d.) Fellows have been hosted in industry or research for a year and some have directed their work towards the technology curriculum, but others who have developed their technological knowledge have done so in relation to teaching science or environmental studies apparently unaware of the contribution their work could make to technology education. It is evident that much is being lost through curriculum segregation of otherwise closely related areas.

Teachers have also funded their own professional development, often subsidised by their schools, through higher education in technology education. Taught papers at the Masters level in technology education have been available through the University of Waikato and Massey University since 1993, and through other institutions since that time, and postgraduate research has been undertaken. A Diploma in Technology Education for graduates has been available through Massey University since 1994, introducing teachers to professional technological 
practice as well as to technology education. Advanced Studies for Teachers (AST) papers in technology education have been available through the colleges of education, including the Auckland College of Education and Christchurch College of Education, where offerings provide progression for teachers who have undertaken development through the Ministry contracts.

Short courses on technology education during school vacations have also been available through the Teachers' Refresher Course Committee (TRCC), and are oriented towards the needs of particular teacher groups, for example, primary teachers or home economics and technicraft teachers wanting to develop their understanding of the new curriculum. More recently, support has become available through an association for technology educators, Technology Education New Zealand (TENZ), established through the University of Waikato Centre for Science, Mathematics and Technology Education Research and the Royal Society of New Zealand, which holds national biennial conferences (the first in 1997), distributes a regular newsletter to members, and supports the development of regional groups.

\section{Resources}

In support of the 1995 curriculum statement in technology, the Ministry of Education has published regular "Updates" and resources, most significantly Implementing Technology in New Zealand Schools: Years 1-8 (Ministry of Education, 1998b) which guides school implementation through the videos and guidebooks of Towards Teaching Technology: Know How 2 (Ministry of Education, 1997b-d). The video resource pursues the recommendation of Ministry-funded research that teachers should experience the culture of technological communities (Jones, Mather \& Carr, n.d). The programmes show a range of professional practice, from engineering and washing machine development to acting and a stage production, but always in a business context. Practice is presented for instruction, not analysis and debate. In "Mighty Milk", for example, there is no critical comment on the release of greenhouse gases through the milk industry's overproduction, the antibiotic treatment of cows for the sale of milk exclusively on the Asian market, or the gendered and monocultural character of management in the industry (Burns, 1997). Guidance for the use of the videos in schools encourages teachers to develop a common rather than a critical understanding of technology.
While Jones (1998) recommends that learning and teaching in technology pay particular attention to reflection of technology practice, France has shown (1997) that though industry links may be a useful short-cut for teacher development of technological knowledge, considerable work is necessary for the preparation of appropriate school programmes. Further, "reflection" of the practice of professional technologists is unrealistic for students who have not had the opportunity to build up the tacit knowledge and potential for "reflecting-in-action" or "in-practice" that is typical of professionals (Schon, 1983). If this uniquely technological thinking is the goal for school technology, students will have to be provided with opportunities for experience-building which will require considerable time to be devoted to any one area. They will also need explicit education in critical questioning, supported by a background in technology studies, if they are to achieve liberating technological literacy (Burns, 1997). The number of technological areas which students will be able to address with any integrity will have to be severely limited.

Endorsement of the development of classroom practice that adopts the values and beliefs of current industrial practice is evident in the support by individual companies and industry groupings for the development of classroom teaching units. They include, for example, Tegel Technopac (Currie, n.d.) and Energy Action (Negawatt Resources, n.d.) which although promoting, respectively, a nutritionally sound diet and environmentally friendly energy conservation, like all of the other resources, fail to critically examine the relationship between values and social groups in the problem-solving activities they entail. Industry support for national events is evident in The BP Technology Challenge which promotes problem-solving competitions, the Telecom Technology Education New Zealand Conference and the ECNZ National Science and Technology Fair. Other less obvious support exists in the contributions of companies to science and technology centres around the country, individual students in the Massey University-based Creativity in Science and Technology (CREST) scheme, and individual teachers in the placement of Science and Technology Teacher Fellows as described earlier.

The practicalities of conducting safe open-ended technological problem-solving activities in classes of over thirty students, however, are not addressed. Although health and safety are specificallyidentified in the Ministry of Education's implementation guide (1998b) and supported with separate guidelines (1998c), there is no provision for 
designated ancillary staffing or additional funding for equipment. Further, as existing technicraft workshops are seen as sufficient for technology activities, there are strict limits on funding for appropriate accommodation that would provide flexible access to information sources and planning, design and practical workspaces. This must reduce the possibility that teachers will be able to introduce the individualised and dynamic activities expected through the curriculum.

\section{Development in schools}

Despite the concerted input into training and associated resourcing by government, industry and professional associations, schools have been slow to develop programmes in technology. They must not only come to terms with the nature of this new subject, but decide how they will organise it in their schools, as a separate subject, "across the curriculum" or in some other way. This is a difficult decision, especially in a school curriculum that has not seen the removal of any core subject to make way for technology.

Case studies of two secondary schools which in 1995 had already begun to introduce technology education found very different approaches, from grassroots initiatives by interested teachers to strong direction by the principal (England, 1996; Nielsen, 1996). In both cases teacher attitudes were generally positive, but problems arose in relation to a lack of resources and time and the variety of understandings of the nature of the new subject held by teachers with different subject backgrounds, observed elsewhere (Jones \& Carr, 1992). Where, in the directed approach (England, 1996), a conceptualisation consistent with a broad view of technology education had originally guided implementation, this reverted to technical skills in the absence of a "high profile" school policy and in the context of changing school personnel. The resultant limited understanding was consistent with parents' expectations that technology education would teach craft and computer skills for enhanced employment opportunities. Nevertheless, teachers' fears that operating costs for technology education would take funds from other areas did not eventuate. These costs did not exceed annual fluctuations in curriculum subject budgets. Two years later a survey of over 100 schools and 350 teachers, almost all from the primary sector, embarking on a professional development contract (Brown, 1997) found only 5 percent of schools had a policy for technology education and 5 percent of teachers felt confident about teaching technology.
Teachers' main concerns, as in the case studies, were about resourcing and the lack of time for this subject in an already crowded curriculum.

While there is clearly enthusiasm among individual teachers and teacher trainers (see, for example, Treadwell, 1997; Barnett, 1994), advice tends to support traditional approaches. Pouwer (1995/96) offers an alternative in drawing attention to the possibilities for technology education available in the different cultural perspectives of Maori and European technological traditions, the respective technological areas developed and the underpinning value positions.

Smits (1998) identifies general concern among primary preservice and inservice teachers about the lack of specification of knowledge in the curriculum. In a 1996 survey of the attitudes toward curriculum subjects held by primary teacher trainees (a follow-up of a survey conducted in 1988), Heald (1998) found technology had replaced mathematics as the least enjoyable subject and replaced Maori as the one seen as least important, but these 1996 trainees considered technology easier than mathematics, science or Maori. A study of secondary graduate technology teacher trainees (Mawson, 1998) followed eighteen trainees through their year of training in 1996, and ten of the newly qualified teachers into their first year of teaching, finding increasing disillusionment among the beginning teachers and, in their schools, "lack of any real progress toward implementing the technology curriculum over the eighteen months period of the research" (p. 4).

In a national survey of student technological knowledge and capabilities in design in 1996, the National Education Monitoring Project (NEMP) examined aspects of technology education among almost 3000 students from 260 schools across years 4 and 8 . Crooks and Flockton (1997) describe wide variations in performance with greater success in tasks involving description and factual knowledge than in those involving explanation and design, which were "not well handled" (p. 4). But the tasks were necessarily much shorter than those which would normally constitute the technological problem-solving activities promoted in the curriculum, and the criteria for assessing an explanation or the quality of ideas, as "strong", "medium" or "weak", were not identified. A survey of student perceptions, administered at the time of the assessment (Eley, 1998), found students at both levels expressed enjoyment of technology at school, but older girls were less enthusiastic than younger girls, and few girls or boys identified technology as a favourite subject. These perceptions, however, need to 
be examined in the knowledge that students were most likely to identify school technology as working with computers, although among the older students designing and making, and homecraft and technicraft subjects were also likely to be identified.

Presently, technology education is mandatory only to year 9 and offers no route to tertiary study in technology. Indeed at year 10, those students who previously would have taken technical subjects revert to this study for the Unit Standards of the Industry Training Organisations. The proposed introduction of Achievement Standards for curriculum subjects from year 10 (Ministry of Education, 1998d) will make possible the study of technology at senior levels, but unless this study is recognised as a prerequisite to tertiary technology study, school technology education will not develop. Tertiary technology may need to rethink its understanding of "technology" and desist from drawing legitimacy in a dependent relationship with science.

\section{Conclusion}

Technology education in New Zealand has evolved from the practical skills of making things, undertaken by the less academic in preparation for work, to a core subject that includes the unique thinking involved in designing, making and evaluating solutions to practical problems. Of all the core subjects, however, it is still the one most closely tied to employment and work (narrowly conceived). Currently curriculum technology largely ignores the moral and ethical considerations of what is to be made (see Olson, 1997; Shannon, 1994), and without this component, and in the service of the economy, the possibilities for future technological change are severely limited.

In the year of implementation of the technology curriculum there are contradictions at Ministry and teaching levels in understandings of technology, and doubts about the commitment of teachers to this new subject. The tradition of progressivism in New Zealand education supports the student-centredness and team-teaching of integrated technological problem-solving, but is not receptive of economic imperatives. However dynamic and iterative the problem-solving process, if the "purpose" is to develop a tangible product guided by consumer preferences, "fitness" will most often be determined by technical considerations, and the requirements of technological change will not be met. Despite the appeal to national identity associated with "kiwi ingenuity" and the egalitarianism of the self-made entrepreneur, it is a false trail to follow since technological change does not take place in this way. Laudan (1984) eschews use of the term "invention" for the reason that it conjures up an erroneous picture of technological change occurring through the flash of inspiration of the "heroic" inventor, when most often it occurs through gradual change involving many anonymous individuals

The introduction of technology education to compulsory schooling occurs at the intersection of two developments. On the one hand, technological change is being drafted into the service of national economic growth in the interests of market competition. On the other, reconceptualisation of technology is demonstrating its embeddedness in the social, and in turn the wider living and physical systems of the planet (Capra, 1997). These "self-organising" systems, Capra suggests, are interdependent and quite unlike the mechanical systems of industrialisation. Changes in one system bring about changes in others such that, for example, the poverty of the South will affect the affluence of the North, and the explosion of fossil-fuelled transportation and industrial farming brings global climate change that can no longer be denied. Technology is not the inevitable application of "value free" science, but is dependent on the politics inherent in existing technologies and the value judgements of the social groups which are positioned to develop them.

For school-leavers to really become "innovators for the future" and for the technology curriculum to achieve "fitness" for this purpose, technology education must be informed by scholarship in the philosophy of technology and must include examination of the values and social organisation that underpin current technological practice and otherwise frame future possibilities. Layton (1993) cautions that to introduce technology education for economic reasons alone heralds its demise since the chance that it will bring about economic growth is slim. The link between increased research and development and economic growth is itself tenuous (Yearley, 1988); Soros has suggested that economic growth may depend more on the abilities of multinationals to move money around the globe, taking advantage of favourable monetary conditions and cheap labour (Soros \& Giddens, 1997). To introduce technology education for liberating technological literacy, however, is likely to meet with fierce resistance from advanced capitalism where it is supported, according to Beck (1994), by collusion between politics and business.

In promoting critical examination of technology practice and the involvement of a wider range of social groups in technological change, 
liberating technological literacy holds promise of more socially and environmentally responsible change (Davies Burns, in press). There is support for pursuing such literacy in school technology, but also concern that it may be beyond the expertise and resources of teachers and schools (France, 1998). A radical view (O'Riley, 1998) suggests that technological problem-solving should be excluded from technology education when the planet has already sustained so much damage. The "purpose" for technology education in the curriculum needs to be reexamined, and any contribution from technological problem-solving no longer devoted to an updated version of "design and make". It must progress beyond the blinkered and ultimately illusory technology "for profit" to technology for quality of life, not only human life, but the life of the planet. Philosopher Mary Midgely (1996) argues that fundamentally we are social beings, sustained not by self-interest (as current market models would suggest), but by emotional fellowship and mutual dependence.

\section{References}

Barnett, J. (1994). Becoming more inventive and innovative. New Zealand Science Teacher, 75, 8-11.

Beck, U. (1992). Risk society: Towards a new modernity. London: Sage.

Beck, U. (1994). The reinvention of politics: Towards a theory of reflexive modernisation. In U. Beck, A. Giddens, \& S. Lash (Eds.), Reflexive modernization: Politics, tradition and aesthetics in the modern social order. Cambridge: Polity Press.

Black, P., \& Harrison, M. (1985). In place of confusion: Technology and science in the school curriculum. London: Nuffield-Chelsea Curriculum Trust.

Bijker, W. E. (1995). Of bicycles, bakelite and bulbs: Towards a theory of sociotechnical change. Cambridge, MA: MIT Press.

Blakeley, J. (1991, August 28). The market is not enough; the economy needs vision. The Press.

Boston, J. (1991). Reorganising the machinery of government: Objectives and outcomes. In J. Boston, J. Martin, J. Pallot, \& P. Walsh, Reshaping the state: New Zealand's bureaucratic revolution. Oxford: Oxford University Press.

Brown, M. (1997). Teacher training and teacher development. Technology enterprise and technology education. Proceedings of a Forum held by The Royal Society of New Zealand. (Miscellaneous Series 44). Wellington: The Royal Society of New Zealand.
Burns, J. (1990). Students' attitudes towards and concepts of technology. Report to the Ministry of Education, Wellington.

Burns, J. (1992, March). Access to technology education. Paper presented to the Ministry of Education Technology Education Consultative Meeting, Wellington.

Burns, J. (1993, December). Empowerment through technology education: The need for an historical focus. Paper presented to the New Zealand Association for Research in Education Conference, Hamilton.

Burns, J. (1997, October). Implementing the technology curriculum: Promise and prospect. Paper presented to the Technology Education New Zealand Conference, Christchurch.

Burns, J., \& Knedler, K. (1984, August). Lead in the environment. Paper presented to the 4th Biennial Conference of the New Zealand Science Teachers' Association (SCICON '84), Wellington.

Capra, F. (1997). The web of life: A new synthesis of mind and matter. London: Flamingo.

Clark, M., \& Vere-Jones, D. (1986). Science education in New Zealand: Present facts and future problems. (Miscellaneous Series 15). Wellington: The Royal Society of New Zealand.

Compton, V., \& Jones, A. (1998). Reflecting on teacher development in technology education: Implications for future programmes. International Journal of Technology and Design Education, 8(2), 151-166.

Cosgrove, M. M., \& Mueggenburg, G. (1986). Refrigeration: A teaching unit for form 6 physics. (Working Paper No. 211). Hamilton: Science Education Research Unit, University of Waikato.

Crooks, T., \& Flockton, L. (1997). Technology assessment results 1996. (National Education Monitoring Report 5). Dunedin: Educational Assessment Research Unit, University of Otago.

Curriculum Corporation. (1994). A statement on technology for Australian schools. Carlton, Vic.: Curriculum Corporation.

Currie, H. (n.d.). Tegel technopac. Auckland: Tegel Foods Ltd.

Davies Burns, J. (in press). Learning about technology in society: Developing liberating literacy. In J. Ziman (Ed.), Technological change as an evolutionary process. Cambridge: Cambridge University Press.

Department of Education. (1984). School Certificate Workshop Technology. New Zealand Education Gazette, 63(2), 22-23.

Department of Education. (1986). Forms 1-4 workshop craft syllabus for schools. Wellington: Government Printer. 
Department of Education. (1987). The curriculum review. Report of the Committee to Review the Curriculum in Schools. Wellington: Government Printer.

Department of Education. (1988a). National curriculum statement: A discussion document for primary and secondary schools. Wellington: Government Printer.

Department of Education. (1988b). Technology education project. Wellington: Department of Education.

Department of Education and Science and the Welsh Office. (1990). Technology in the national curriculum. London: HMSO.

Doig, M. (1991). Setting government science priorities. New Zealand Science Review, 48(1-2), 10-14.

Durie, A. (1997). Maori and technology. In J. Burns (Ed.), Technology in the New Zealand curriculum: Perspectives on practice. Palmerston North: Dunmore Press.

Education Forum. (1994). Technology in the New Zealand curriculum: A submission on the draft. Auckland: The Education Forum.

Eley, E. (1998). Technology: What our primary students think about it. set Special 1998: Technology, Item 6, 1-4.

Elley, W. (1996). Curriculum reform: Forwards or backwards? Delta, $48(1), 3-10$.

England, C. (1996). A case study of the economics of the introduction of technology education at a co-educational secondary school. Unpublished MEd research project., Massey University, Palmerston North.

Farmer, B., \& Hodson, B. (1991). What do you mean by technology? New Zealand Science Teacher, 67, 6-10

Fergusson, D. (1997). How the technology curriculum came in to being... Network Voice, 14-15.

France, B. (1997). Realising the technology curriculum: Professional development in biotechnology education. Unpublished DPhil. thesis, University of Waikato, Hamilton.

France, B. (1998, July). Technological literacy: A realisable goal or a chimera? Paper presented to the Australasian Science Education Research Association Conference, Darwin.

Gee, J. P. (1996). Social linguistics and literacies: Ideology in discourse. (2nd ed.). London: Taylor and Francis.

Giddens, A. (1994). Beyond left and right: The future for radical politics. Cambridge: Polity.
Green, W. (1984, August). Science, technology and society education. Proceedings of the 4th Biennial Conference of the New Zealand Science Teachers' Association (SCICON '84), Wellington.

Hawk, K. (1997). Technology development schools evaluation. Final report. Prepared for the Ministry of Education. Educational Research and Development Centre, Massey University, Albany Campus.

Heald, G. (1998). Attitude of primary teachers to mathematics. Unpublished research report, Rangi Ruru Girls' School, Christchurch.

Hodson, D., \& Farmer, B. (1992). Technology education: The need for breadth and balance. Delta, 46, 31-39.

Jenkins, E. W. (1994). The relationship between science and technology in the New Zealand curriculum. Auckland: The Education Forum.

Jesson, J. (1991). Technology education: Bringing the debate home. New Zealand Science Teacher, 68, 39-42.

Jones, A. (1998, November). The development of technology education in New Zealand: From policy to practice. The Technology Teacher, pp. 1-18.

Jones, A. T. (1990). Technology and science education. Science and Mathematics Education Papers - 1990, pp. 202-227.

Jones. A., \& Carr, M. (1992). Teachers' perceptions of technology education. Working Paper 502. Centre for Science and Mathematics Education Research, University of Waikato, Hamilton.

Jones, A., \& Carr, M. (1993a). Towards technology education. Vol. 1. Working papers from the first phase of the learning in technology education project. Centre for Science and Mathematics Education Research, University of Waikato, Hamilton.

Jones, A., \& Carr, M. (1993b). Analysis of student technological capability. Working Paper 504. Centre for Science and Mathematics Education Research, University of Waikato, Hamilton.

Jones, A., Mather, V., \& Carr, M. (n.d.). Working with teachers to enhance student technological capability. Working Paper 505. Centre for Science and Mathematics Education Research, University of Waikato, Hamilton.

Jones, A., Verbowski, E. \& Carr, M. D. (n.d.). Development and management of technological activities. Working Paper 503. Centre for Science and Mathematics Education Research, University of Waikato, Hamilton.

Kerse, D. (1989). Technology within a primary school. New Zealand Science Teacher, 61, 55. 
Kimbell, R. (1994). Progression in learning and the assessment of children's attainments in technology. International Journal of Technology and Design Education, 4(1), 65-83.

Kline, R. (1987). Science and engineering theory in the invention and development of the induction motor 1880-1900. Technology and Culture, 1(1), 1-10.

Laudan, R. (1984). Cognitive change in technology and science. In R. Laudan (Ed.), The nature of technological knowledge (pp.83-104). Dordrecht: Reidel.

Layton, D. (1993). A school subject in the making? The search for fundamentals. In D. Layton (Ed.), Innovations in science and technology education. Vol. 5. Paris: UNESCO.

Layton, D. (1992). Reconceptualising science and technology education for tomorrow. Science, Technology and Development, 10(2), 141-161.

Mawson, B. (1998). Facing the challenge: Student teachers, secondary schools, and technology, set Special 1998: Technology, Item 5, 1-4.

McKinley, E. (1996). Towards an indigenous science curriculum. Research in Science Education, 26(2), 155-167.

Midgley, M. (1996). Utopias, dolphins and computers: Problems of philosophical plumbing. London: Routledge.

Ministry of Education. (1991a). The achievement initiative. New Zealand Education Gazette, 70(7), 1-2.

Ministry of Education. (1991b). The national curriculum of New Zealand: A discussion document. Wellington: Learning Media.

Ministry of Education. (1992). So this is technology! Wellington: Learning Media.

Ministry of Education. (1993a). Technology in schools. Wellington: Learning Media.

Ministry of Education. (1993b). Technology in the New Zealand curriculum draft. Wellington: Learning Media.

Ministry of Education. (1993c). Science in the New Zealand curriculum. Wellington: Learning Media.

Ministry of Education. (1993d). Working together: Building partnerships between schools and enterprises. Wellington: Learning Media.

Ministry of Education. (1994a). English in the New Zealand curriculum. Wellington: Learning Media.

Ministry of Education. (1994b). Te tauaki marautanga putaiao: He tauira. Wellington: Learning Media.

Ministry of Education. (1995). Technology in the New Zealand curriculum. Wellington: Learning Media.
Ministry of Education. (1997a). Social studies in the New Zealand curriculum. Wellington: Learning Media.

Ministry of Education. (1997b). Towards teaching technology: Know how 2. Video Programmes. Wellington: Learning Media.

Ministry of Education. (1997c). Towards teaching technology: Know how 2. Guide book for facilitators. Wellington: Learning Media.

Ministry of Education. (1997d). Towards teaching technology: Know how 2. Book two: Support material. Wellington: Learning Media.

Ministry of Education. (1998a). Te tauaki hangarau $i$ roto $i$ marautanga o Aotearoa. Wellington: Learning Media.

Ministry of Education. (1998b). Implementing technology in New Zealand schools: Years 1-8. Wellington: Learning Media.

Ministry of Education. (1998c). Safety and technology: A guidance manual for New Zealand schools. Wellington: Learning Media.

Ministry of Education. (1998d). Achievement 2001: Qualifications for 16 to 19 year olds. Wellington: Ministry of Education and New Zealand Qualifications Authority.

Ministry of Research, Science and Technology. (1991). Glossary of terms for scientific and technological activities in New Zealand. Wellington: Ministry of Research, Science and Technology.

Ministry of Research, Science and Technology. (1998). Science and technology interest, understanding and attitudes in the New Zealand community. Wellington: Ministry of Research, Science and Technology.

Ministry of Research, Science and Technology and Ministry of Education. (1992). Charting the course. Report of the Ministerial Task Group Reviewing Science and Technology Education. Wellington: Learning Media.

Monteith, W. (1987). Making money - a challenge for technology and the school leaver. New Zealand Science Teacher, 52, 44-46.

Monteith, W. (1992, March). Wealth creation. Paper presented to the Ministry of Education Technology Education Consultative Meeting, Wellington.

Murphy, P., \& McCormick, R. (1997). Problem solving in science and technology education. Research in Science Education, 27(3), 461-481.

Negawatt Resources (n.d). Energy action: An energy resource for schools. Wellington: Negawatt Resources.

New Zealand Government. (1986). Key to prosperity: Science and technology. (The Beattie Report). Report of the Ministerial Working Party. Wellington: Government Printer. 
Nielsen, M. J. (1996). Teacher views of technology education and how it could be implemented into a rural high school. Unpublished MEd Research Project, Massey University, Palmerston North.

Olson, J. (1997). Technology in the school curriculum: The moral dimensions of making things. Journal of Curriculum Studies, 29(4), 383-390.

O'Neill, A-M., \& Jolley, S. (1996/97). Privatising curriculum. Constructing consumer society. The technology curriculum: The politics of food - women's work? To high tech ... or oblivion. Delta, $48(2), 49(1), 221-247$.

O'Riley, P. (1998, December). Troubling research: Regenerating technology discourses and educational inquiry as "mutual learning" conversations. Paper presented to the New Zealand Association for Research in Education Conference, Dunedin.

Pacey, A. (1983). The culture of technology. Oxford: Blackwell.

Paechter, C. (1991, September). Subcultural retreat: Negotiating the design and technology curriculum. Paper presented to the British Educational Research Association Conference, Nottingham.

Pitt, J. C. (1990). The myth of science education. Studies in Philosophy and Education, 10, 7-17.

Pouwer, M. (1995/96). Opportunities for bicultural technology education: A Pakeha/European teacher's point of view. New Zealand Science Teacher, 80, 7-10.

RoyalSociety of New Zealand. (n.d.). New Zealand Science and Technology Teacher Fellowship profiles: 1994-95. Wellington: The Royal Society of New Zealand.

RoyalSociety of New Zealand. (n.d.). New Zealand Science and Technology Teacher Fellowship profiles: 1996-97. Wellington: The Royal Society of New Zealand.

Schon, D. (1983). The reflective practitioner. London: Temple Smith.

Shannon, M. J. (1994). Designing education for life on earth. International Journal of Technology and Design Education, 4(3), 289-297.

Smits, R. (1998). Knowledge "just-in-time": Why doesn't the technology curriculum tell us what to teach? set Special 1998: Technology, Item $2,1-4$.

Snook, I. (1997,December). Technology education: A new subject or an ideologicalstrategy? Paper presented to the New Zealand Association for Research in Education Conference, Nelson.
Solomon, J., \& Hall. S. (1996). An inquiry into progression in primary technology: A role for teaching. International Journal of Technology and Design Education, 6(3), 363-282.

Soros, G., \& Giddens, A. (1997, October 31). Beyond chaos and dogma..., New Statesman, pp. 24-27.

Staudenmaier, J. (1985). Technology's storytellers: Reweaving the human fabric. Cambridge, MA: MIT Press.

Treadwell, M. (1997). Innovation and ingenuity: Interpreting the technology curriculum in New Zealand. Auckland: Teachers@work.

Verbowski, E. (1992a). Technology education for informed decision making. New Zealand Science Teacher, 69, 9-11.

Verbowski, E. (1992b). The goal of technology education: Capability or literacy? New Zealand Science Teacher, 69, 12-15.

Visser, H., \& Bennie, N. (1995). Schools' opinions on the draft statement: Technology in the New Zealand Curriculum. Bulletin, 5, 55-62. Wellington: Research Section, Ministry of Education.

Walsh, B. (1987). Certech: The secondary-tertiary student flow 1979-1986, and the implications for a changing economy. Palmerston North: Massey University.

Winner, L. (1980). Do artifacts have politics? Daedalus, 109, 121-136.

Yearley, S. (1988). Science, technology and economic success. In S. Yearley, Science, technology and social change (pp. 95-119). London: Unwin Hyman.

\section{The author}

Janet Davies is a senior lecturer in the Department of Educational Studies and Community Support at Massey University. She teaches postgraduate courses in science and technology education and supervises research in these areas, and in learning and teaching more generally. Her research interests are in the learning process, especially conceptualisation and reasoning, and the significance of context in this regard. She has been conducting technology education research for over a decade, and has a background of interest in research methodology, chemistry education and gender issues. 